\title{
The Starlink Program: Training for Security Sector Reform in Armenia, Azerbaijan, Georgia, Moldova, and Ukraine
}

\author{
Sami Faltas and Merijn Hartog *
}

For the last two years the Center for European Security Studies (CESS) has demonstrated that training can serve as a useful tool to actively stimulate democratic governance in the security sectors of transitional countries in the former Soviet Union. Between 2006 and February 2008, CESS implemented a program called Starlink in five PfP countries in Eastern Europe and the South Caucasus: Armenia, Azerbaijan, Georgia, Moldova, and Ukraine. The Starlink program (which is short for Security, Transparency, Accountability and Reform: Linking the Security Sectors of Armenia, Azerbaijan, Georgia, Moldova, and Ukraine to the European Mainstream) was designed to help connect the beneficiary countries to the wider European security community by promoting reforms and democratic governance of the security sector. More specifically, the focus is the development and delivery of training materials and courses for key groups in the countries concerned. While Starlink pays specific and separate attention to various communities within the security sector - such as military, intelligence, and law enforcement agencies - it adopts a comprehensive, or "whole government" approach, emphasizing the need for close cooperation and coordination between these communities. The Starlink program was subsidized by the Netherlands Ministry of Foreign Affairs; in Armenia and Azerbaijan, the local OSCE missions kindly cofinanced Starlink.

In this article we will deal with CESS' Starlink program, its focus on training courses and modules, the added value of simulation exercises, and the purpose of the program: the promotion of democratic governance, with a special emphasis on the security sector. We will also draw lessons learned from the original Starlink program. In our conclusion, we will look at the options for Starlink's future. Besides discussing its possible outreach and scope, we will demonstrate the contribution of Starlink to international security sector initiatives, such as the OECD's DAC handbook ${ }^{1}$ and NATO's PAP-DIB.

\section{The Principles of Democratic Governance}

Good governance is epitomized by predictable, open and enlightened policy-making, a bureaucracy imbued with a professional ethos acting in furtherance of the public good, the rule of law, transparent processes, and a strong civil society participating in public affairs. Poor governance (on the other hand) is characterized by arbitrary policy making, unaccountable bu-

\footnotetext{
* Dr. Sami Faltas is the Executive Director of the Centre for European Security Studies (CESS), Groningen, the Netherlands. Mr. Merijn Hartog is a Program Manager at CESS and was principal coordinator of the Starlink program.

1 The OECD DAC Handbook on Security System Reform. Supporting Security and Justice (Paris: Organisation for Economic Cooperation and Development, 2007).
} 
reaucracies, unenforced or unjust legal systems, the abuse of executive power, a civil society unengaged in public life, and widespread corruption. ${ }^{2}$

CESS is an independent institute for research, consultancy, education, and training located in Groningen, the Netherlands. Since its establishment in 1993, the Center has been promoting democratic approaches to security policy. Working with NGO and government partners all over Eastern Europe, Southeastern Europe, Turkey, and the southern Caucasus, it organizes seminars, courses, debates, and research projects on democracy and defense. The aim of promoting transparent, accountable, and effective governance of the security sector lies at the heart of all CESS activities. Before we go deeper into the specific features of the Starlink program, we first need to identify the principles of democratic governance.

These principles, on their face, are relatively simple: the state must inform the citizens; politicians and officials must account for their actions; and the law applies equally to all citizens, high and low. The principles of democratic governance are clear enough, and everyone is in favor of them, at least in theory. In practice, they meet a lot of resistance, and it is not easy to apply the principles consistently. Unfortunately, democratic governance is most difficult to achieve where it is most urgently needed, namely in the security sector.

Security forces must obey the law and account for their actions to the elected representatives of the people. They deal with sensitive information, and are naturally inclined to be too secretive about their work. The less transparent they are, the less the legislature, the judiciary, and the media can hold them to account. And the less accountable they are, the greater the risk that they will become corrupt, violate the rights of citizens, become a state within the state, and wield undue political power. Thus a lack of democratic governance can turn the armed agencies of the state into a threat to the population and the constitution. Most politically literate people in the old and new democracies acknowledge this today. But the consensus begins to crumble as soon as you start discussing the practical implications of democratic control: "Surely you don't mean all security officials? What about spies? What about antiterrorist operations? Isn't there a limit to the information parliament can demand? Are politicians, magistrates, and journalists interested in scrutinizing the security forces? And would not this prevent soldiers, policemen, and spies from doing their job? Can a country under threat afford such a luxury?"

If democratic governance in the security sector is to be more than an empty phrase, these questions must be faced and answered. General answers are available in the scholarly literature, as well as in the reports of a few think tanks like CESS. But specific answers are also needed, responses geared to the characteristics and circumstances of a particular sector or country, and many of those are not yet available. What works for the police may not work for intelligence agencies, and an approach that is good for Ukraine may be bad for Turkey. There is a need for tailored approaches, based on general principles of good governance. Obviously, the need is greatest in de-

2 Governance: The World Bank's Experience (Washington, D.C.: The World Bank, 2004). 
veloping democracies, but transparency and accountability in the security sector are a never-ending challenge in mature democracies as well. In the West, topics of late include the improper detention and the torturing of people suspected of terrorism, as well as the tapping of telephone calls and e-mail traffic.

When countering the lack of democratic governance in the security sector, the obvious remedy is to put in place strong checks and balances. In well-governed countries, various branches of government hold each other in check. Politicians and civil servants face constant scrutiny by parliament, the judiciary, the media, and civil society. If they abuse their power, they risk disgrace, dismissal, and punishment. This system is built on laws, institutions, and a culture of accountability. It does not guarantee honest behavior by all public officials all of the time. But it drives home the message that honesty is the best policy.

\section{Training for Security Sector Reform}

\section{I hear and I forget. I see and I remember. I do and I understand. ${ }^{3}$}

Now that the principles have been discussed, we will shift our attention to the practice of democratic governance in security policy. Here one of the biggest difficulties is that the politicians, civil servants, journalists, and civil-society groups who are supposed to scrutinize the security sector are often poorly prepared and sometimes less than eager to do so. Many young democracies have the laws and institutions required for democratic governance, but lack a culture of accountability. Training is one way to tackle this problem.

After years of organizing conferences and seminars on defense and security issues in Eastern Europe, CESS decided in 2005 that the time was ripe to develop a training program which was supposed to go significantly beyond earlier projects. We used to organize policy conferences and seminars that dealt with security and defense issues. Audiences were large, and debate was usually stimulated by speeches and plenary panel discussions. For the Starlink program, we developed and compiled training modules and organized training workshops on security sector reform. Audiences were small, but diverse, and debate was stimulated by experienced instructors on the basis of specialized modules. In general, you could say that within the Starlink context a higher level of pro-activity is expected from the participants, and is actively pursued by experienced trainers.

In the first half of 2005 the Starlink program was designed, after which the final proposal was submitted. CESS argued that three days of instruction in the local language would provide Starlink trainees with a good understanding of democratic governance and the specific challenges it poses in the security sector. There are three types of courses: one pays special attention to the defense establishment, another to law enforcement, and a third to intelligence. In each course the trainees are drawn from various parts of government and society. In February 2006 the first training course was or-

3 Confucius, Chinese philosopher and reformer (551-479 BCE). 
ganized, taking place in Kiev, Ukraine, and dealing with democratic governance in the defense sector.

In a nutshell, a Starlink course starts with an interactive introduction to the principles and fundamentals of democratic governance. At the end of the first morning, trainees apply these principles in discussing a recent political event in their country. If the stage has been set successfully, the trainees are now sufficiently confident and comfortable to be able to critically discuss their own government's actions in the presence of foreigners. On the afternoon of the first day, one or two topics of a more operational nature (e.g., integrated border management, fighting terrorism, or human rights of defense personnel) are scheduled. The second day is entirely devoted to a role-play exercise. A real challenge of Starlink was to get our message across and to create a useful learning experience, which is why we decided to build in these one-day simulation games within each Starlink course. Each game is set in the fictitious post-Soviet republic of Croania, somewhere south of Russia. The third day of the course is taken up by a "post-mortem" analysis of the role-play, a continuing discussion on parliamentary oversight, the evaluation of the course, and the awarding of certificates.

Three classroom experiences stand out, and are worth reporting in greater detail. The first is the dramatic impact of the role-play exercise in which trainees enact a parliamentary hearing on a serious misdemeanor by the Croanian government. (There is some variation in this exercise depending on the audience for the course. For the defense course, we developed a role-play on the illegal purchasing of military uniforms by the Minister of Defense; in the law enforcement course the role-play deals with abusive behavior of the Croanian police towards immigrants; and in the intelligence course, the game centers around the decision-making process preceding the deployment of troops to yet another fictitious country.) When we tried the defense role-play out with students in the Netherlands, the hearing was conducted in the orderly and serious manner one would expect from the Second Chamber in the Netherlands.

This was not the case in cities like Kiev, Baku, or Tbilisi. In these deliveries of the course, the mock parliamentary committee proved unable to actually hold the mock government accountable, and many of the things that one would expect to go wrong in a young and shaky democracy indeed went seriously out of hand. Ministers and their officials intimidated the parliamentary committee, the committee engaged in personal attacks against witnesses, one minister actually threatened a journalist with his criminal connections, and private and party interests consistently took precedence over parliamentary sovereignty. From an educational point of view, this was ideal. We were able to praise the trainees, saying that this was exactly how such a hearing would go in Croania. In most courses, the participants at this stage added that things would not go any differently in Croania than they would in their own countries. Then we went on to flag everything that would have gone in a different fashion in a mature democracy. This struck home more powerfully than any lecture or handbook could have done.

A second experience that stood out was the fact that we aimed for a highly interactive style of teaching in Starlink. Participants are expected — indeed, they are pressedto engage the trainer and each other in discussion and to contribute their knowledge, especially of local conditions. In practice, we find that Eastern European government 
officials need to get used to this style of teaching. We have been able to establish a workshop atmosphere within the first few hours. We find that in practice our instructors employ a variety of teaching styles, ranging from continual dialogue with the students to PowerPoint bombardment. The students said they appreciated this pedagogical diversity, but we continued to strive for training rather than lecturing.

Another classroom experience worth relating is the adamant and consistent assertion by trainees that there is a great and urgent need in their country for this kind of hands-on training on democratic governance in practice, both within and beyond the security sector. One of the distinctive features of the Starlink program is that it is more than a training effort. It puts in place generic teaching packs - the modules - that were tested by CESS in the Starlink context, but could also be taught by local institutes in the five Starlink countries without significant additional input from CESS. That is why over the past three years we have tried to assist local universities, military and police academies, and NGOs in setting up security sector reform training courses of their own, based on the Starlink material. Today we are still talking to government departments, universities, and NGOs in the beneficiary countries about ways of gradually transferring the teaching of such courses to local organizations, but to be honest, this part of Starlink is difficult to accomplish and requires more time and effort than we had expected at the launch of the program. Another feature of the Starlink training courses is that, even though to this point they have only been held in Armenia, Azerbaijan, Georgia, Moldova, and Ukraine, they can in principle be taught anywhere else in the world and can serve a wide variety of audiences. Of course, each time they are used, these building blocks must be modified to suit the specific needs of the audience in question.

\section{Unique Elements of Starlink}

Due to the intensive style of teaching, each Starlink course can train a maximum of twenty-five young professionals. To get around this limitation in size, and thus to support local training initiatives, the Starlink program has commissioned the delivery of full training packages, which consist of the modules accompanied with everything else an instructor needs to teach a particular Starlink subject. That is why every training module has an extensive teacher's manual and handouts for the trainees. Exercises and PowerPoint presentations are integrated in the modules. All the material is available in English and meets the highest presentation standards. Internationally renowned experts are developing these training packages, which are owned by CESS but will be made available for free to bona fide users around the world. For the last three years the authors taught the modules in the Starlink courses. Subsequently, the modules were often taught by other experts, sometimes from former communist countries. In order to be universally useful, the modules are generic.

If successful, Starlink will help the countries concerned to develop the most important resources required for security sector reform, namely people who are prepared to launch, implement, and sustain the reforms. But it will do more. Starlink is creating a range of training modules on security sector reform that can be delivered to many kinds of audiences all over the world, in various styles and formats. These modules are 
currently being developed by international experts on the subject. They can be selectively assembled to form courses, and will have to be adapted to the needs of the audience in each case. So while the Starlink modules are generic, the Starlink courses are specifically designed for particular users.

We feel that the Starlink program is unique because of the combination of eight strengths. The uniqueness lies in the combination, not so much in the characteristics themselves.

- We taught the course in the countries where the students are from; we do not bring them to the Netherlands.

- We used simultaneous interpretation during the entire course, which is especially useful for the role-play. We are convinced that the game will be conducted in a more realistic fashion if the trainees are allowed to discuss in their own language. (All the modules and the three role-plays are translated into the languages of the five countries where we have worked up to this point).

- We aimed at having mixed audiences made up of representatives from government and parliament, but also from civil society, in the classroom, because when the trainees are working together they not only improve their knowledge of the subject, but also their understanding of the responsibilities and difficulties faced by their fellow students. One trainee pointed out that this was the first time that representatives of the government and civil society in her country sat down at the same table to discuss security policy.

- Within the target groups, Starlink focused on young professionals, since they are most interested in (and most capable of) acquiring new knowledge and skills, and because they are the cadres who can be expected to implement structural reforms in government, society, and the media.

- We used the simulation exercise as an important teaching tool. It basically showed the students what we taught them on the first, theoretical, day. In most cases the students were elated about the game and the way the problems of democratic oversight are made tangible. And exactly that is the crux of the simulation games - it makes the students feel what democratic governance is really about.

- Within Starlink we developed teaching material for local use, as discussed above.

- Starlink invited experts from Eastern Europe to pass on lessons they had learned to other previously communist countries. It actively engaged these neighboring countries' experiences and assisted in building an international network of NGOs interested in security sector reform.

- Starlink considered the security sector as a whole in the three courses, not exclusively the defense establishment, but also law enforcement and intelligence. And we did not look only at the executive side of governance; the role of parliament and civil society received just as much attention. With this comprehensive approach Starlink emphasized the need for close cooperation and coordination between the different actors in the security community. 


\section{Challenges in Implementation}

Although these assets are clear, and the combination of these elements is important to bear in mind, Starlink (not surprisingly) also encountered difficulties during its implementation phase. From these difficulties we must draw lessons learned that should be taken into account when developing new training programs. It could also serve as an example for other NGOs that are planning to submit a training project of their own.

The Starlink program has reached about 60 trainees in Armenia, Azerbaijan, Georgia, and Moldova, and around 120 in Ukraine. This is only a small fraction of the government, parliament, media, and civil society representatives with a need for such instruction. It was clear from the outset that this program would focus on the development, testing, fine-tuning, and introduction of useful training programs, and would not be capable of providing instruction to large numbers of people. And exactly that was the reason why we were quite ambitious in formulating our project goals. To counter the danger of only reaching a very small portion of the security community of our target countries, we stated that we needed to stimulate local training institutions to add our modules to their course curriculum. Unfortunately, we did not live up to this goal we had set for ourselves.

We argued that creating local ownership would set in motion a process that would continue to add to the pool of local professionals equipped for security sector reform. And indeed, in the long run, local ownership will decide whether the Starlink approach, which is now acknowledged to be relevant and useful, takes root in the targeted countries. Thanks to the enthusiasm, professionalism, and excellent contacts of our local partners, Starlink training materials are indeed being used by a few local training organizations, but it takes place sporadically and on an ad-hoc basis. That is why we now estimate that, without continued help and encouragement from CESS, few if any local organizations will launch sustainable training programs based predominantly on Starlink material. This obviously requires more time and effort than we had expected at the beginning of this program.

Although we expect the use of our modules to increase, since all of them became available just recently, we are not entirely satisfied with our own achievements in this respect. We had hoped to make a bigger and more lasting impact on training efforts in the countries of operation. When designing this program, we must have underestimated the time and effort required to promote the use of Starlink material. Besides, we believe the constraining factor here is the lack of capable trainers and schools that can organize the courses year after year. Therefore, we believe that when we are extending the Starlink program, we should include an effort to train local trainers and help local colleges to adopt Starlink. This assistance could take the following forms:

- Training and certifying trainers (perhaps in cooperation with universities from the Netherlands)

- Familiarizing schools with the program and its teaching methods, and advising them on how to select trainers and organize courses

- Helping schools to organize pilot courses. 
Another difficulty we encountered in all the beneficiary countries has to do with the level of participation. Teaching three days in a row is something which many participants were not familiar with, and it took most of them a lot of effort to convince their bosses that they indeed had to be present for the entire course. Unfortunately this did not work out entirely as we hoped. Some participants only attended for one or two days or just part of a day, which presented a particular challenge for the proper completion of the role-play. Already on the first day of the program the instructor was forced to divide the roles; when participants later had to cancel on the role-play, big problems occurred. Lucky enough we were able to solve these problems in almost all cases, usually by giving the foreign instructors a role or by skipping the less important roles, but the fact that they surfaced on such a regular basis caused a great deal of crisis management, stress, etc. In our opinion there is just one measure to counter this complication: taking the participants to a place outside the capital. Although the costs of the course will increase if the meeting is held offsite, since all participants will have to stay in a hotel, it is definitely worth the added expense.

\section{Options for Starlink's Future: Outreach, Scope, and Foreign Policy Efforts}

In this concluding section we will look at the options for Starlink's future. Besides discussing its possible expansion in both geographic reach and topical scope, we will demonstrate the contribution of Starlink to international security sector initiatives, such as the OECD's DAC handbook and NATO's PAP-DIB. In essence, our ideas with regard to the future of Starlink can be divided along the following lines:

- Widening the outreach of the Starlink program to other countries and regions

- Deepening the scope of the project by developing new modules, geared to the specific requirements of new countries

- Connecting Starlink with other foreign policy efforts.

\section{Widening the Outreach of the Starlink Program}

In February 2008, CESS and its partners in Armenia, Azerbaijan, Georgia, Moldova, and Ukraine concluded their Starlink program. CESS will continue this successful program in other ways. Most immediately, it will take Starlink to Kazakhstan and the Western Balkans.

Following the roll-out of the Starlink program in Eastern Europe and the South Caucasus, simple logic dictated that we should start exploring the other side of the Caspian Sea: Central Asia, but more particularly, Kazakhstan. With the other four former Soviet Central Asian nations being either much more authoritarian, too unstable, too poor, or a combination of all three, Kazakhstan emerges as the West's logical ally in this strategic energy-rich region. We believe there is a need for the development of human capacity for democratic governance in the security sector of Kazakhstan, as the country is engaged in a process of reforms that will improve oversight of the security agencies, enable the country to fulfill the commitments it undertook in its Individual 
Partnership Action Plan of 2006, and enhance Kazakhstan's standing within the OSCE. In 2010, the presidency of the OSCE will for the first time rotate to Kazakhstan. Moreover, in 2007 and 2008, the Netherlands Embassy in Astana is serving as the NATO Contact Point Embassy (CPE) in Kazakhstan. The proposed Starlink program will serve as one of the Netherlands' activities in its role as NATO CPE.

Kazakhstan has put in place several of the laws and institutions required for democratic oversight of the security sector, and others are likely to follow. However, Kazakhstan still has some way to go to foster a culture of accountability. Here Starlink training courses will be helpful. The delegation of the EU in Kazakhstan has confirmed this impression.

After this Starlink program in Kazakhstan, CESS will start working in the Western Balkans to deliver an adapted Starlink program. The problems and needs of the countries of the Western Balkans differ significantly from the countries in which we have been implementing the Starlink program so far. One can say that the countries of the Western Balkans have advanced further in their transition, and therefore are facing other difficulties in the field of democratic governance of the security sector. To suit these needs, we feel it is necessary to design new training courses, compose new modules, and to consider each country on its own merits.

Unlike the initial Starlink program, which focused on three pillars of the security sector, Starlink in the Western Balkans will focus mainly on only one of these pillars, namely the defense sector. The reason we have chosen to limit ourselves to the defense sector in this new Starlink program is because there is a clear need for this focus. This was stressed by our NGO partners in Bosnia and Herzegovina, Montenegro and Serbia, the Netherlands Embassy in Belgrade, the Jefferson Institute's office in Podgorica, which assists the Montenegrin Ministry of Defense, and the Defense Committee of the Parliament of Montenegro. Furthermore, there is not as much assistance available in the defense field as, for instance, in the law enforcement sector. For the defense sector, CESS designed focused three-day training courses that address the issues relevant to the subject countries in the phase of the transition they are currently in.

In this respect we developed four training courses, each addressing a different subject that suits the needs of the target. The first course deals with how to get effective "right-sizing" and reorganization within defense administrations going: e.g., laying off civilian and military personnel and facilitating their reintegration into society; reorganizing the remaining staff; and enhancing the efficiency of defense organizations. The second course is designed to acquaint practitioners with the drafting and discussion of defense policy documents, including defense budgets. Furthermore, specific attention will be paid to the role of parliament vis-à-vis the defense sector. The third course deals with international law and its importance for the defense sector, both on the national and international stage. The fourth training course will discuss the international dimension of the military. Subjects to be discussed comprise the functioning of structures of NATO and the ESDP, the process and prerequisites for joining the EuroAtlantic structures, and the deployment of troops within the framework of peace support operations. 


\section{Deepening the Scope: Development of New Modules}

At the end of the initial Starlink program, nine modules were finalized on subjects related to democratic governance in the defense, law enforcement, and intelligence sectors. During the course of the Starlink program we regularly received requests for new modules on subjects like police reform, human resources management for the security sector, fighting corruption in the security sector, designing and managing SSR programs, etc. We assessed such requests according to two criteria: Are they relevant to the countries in which we are working? And are we the right people to develop it?

With regard to the first question, the answer is simple. When we decided to widen the outreach of the Starlink program to the Western Balkans region, the existing list of modules was no longer sufficient. As mentioned in the previous section, we decided to restrict ourselves to the defense sector, so it made sense that new, more in-depth modules had to be developed. And with regard to the second question, no, we are not always the right people to develop new modules. Here at CESS we ourselves can compose modules about theoretical topics like the role of parliament in defense issues, the fundamentals of democratic governance, and democratic oversight of the intelligence community, but within the original Starlink program we had to approach experts from our extensive network to write modules that are more operational by nature: e.g., combating organized crime and terrorism, developing defense policy documents, etc. The same goes for "new" topics like human resource management for the security sector. The knowledge within the network of CESS is indispensable to the quality of programs like Starlink.

\section{Connecting Starlink with other Foreign Policy Efforts}

In the autumn of 2005, our government designated our Starlink program as the Netherlands' contribution to NATO's Professional Development Program for Ukraine. This was an afterthought and a coincidence, because the two programs happened to be launched at the same time. The government was thus able to use Starlink to serve an additional purpose that was entirely in line with the nature and aims of our program. We believe there would be a wider scope for usefully connecting Starlink to other foreign policy efforts, for instance to PAP-DIB and OECD DAC.

Although Starlink was not officially announced as a part of NATO's Partnership Action Plan on Defense Institution Building (PAP-DIB), it clearly contributed to its objectives. More specifically, our Starlink training efforts contributed to objective 5.1- "Develop effective and transparent arrangements for the democratic control of defense activities, including appropriate legislation and coordination arrangements setting out the legal and operational role and responsibilities of key state institutions in the Legislative and Executive branches of Government"-and objective 5.2: "Develop effective and transparent procedures to promote civilian participation in developing defense and security policy, including participation of civilians in governmental defense institutions, cooperation with non-governmental organizations and arrangements to ensure appropriate public access to information on defense and security issues." 
Especially through its modules on the fundamentals and principles of democratic governance and its three role-play exercises, Starlink helped raise awareness in Armenia, Azerbaijan, Georgia, Moldova, and Ukraine on issues like the role of parliament in overseeing the executive, the importance of civilian direction within the Ministry of Defense, and the two golden rules of democratic governance: the people have the right to know what is being done and spent in their name (transparency), and the government has the responsibility to reveal, explain, and justify what it does and what it spends (accountability).

PAP-DIB has a program called Education for Reform and a support group of training organizations that calls itself the Friends of PAP-DIB. The Starlink material is perfectly suited to this effort, as was acknowledged at several meetings of the Friends. This circumstance presented itself as an opportunity for the Netherlands to play a prominent role in PAP-DIB.

Alongside its contribution to PAP-DIB, CESS is one of several institutes that are teaching and propagating the approach developed in the OECD DAC Handbook on Security System Reform. Starlink training tools are being used in OECD-sponsored training courses, and Starlink courses are making use of the OECD material. One of the distinctive features of the OECD DAC approach to security sector reform is that it focuses mainly on developing countries, while Starlink has so far mostly addressed the needs of transitional countries in the former Soviet Union.

We expect to connect Starlink to other foreign initiatives in the future when the program is up and running in the Western Balkans. Here a linkage could be made with the RACVIAC Center in Croatia, in the form of continued support from CESS for their "Democratic Control of the Armed Forces" course. We also hope to cooperate with them in our efforts to get a serious train-the-trainer program off the ground within the new Starlink program in the Western Balkans. We could, for instance, train potential trainers at the RACVIAC premises. These potential trainers should be educated in order for them to be capable (and certified) to teach the Starlink modules at their own institutes/universities/academies in their home countries. The candidates should not only come from the five Western Balkan countries, but also from the previous Starlink beneficiary countries and similar transition countries. 
THE QUARTERLY JOURNAL

\section{Bibliography}

Governance: The World Bank's Experience . Washington, D.C.: The World Bank, 2004.

The OECD DAC Handbook on Security System Reform. Supporting Security and Justice. Paris: Organisation for Economic Cooperation and Development, 2007. 